\title{
Original
}

\section{Mice Treated with an Antibiotic Cocktail Containing Metronidazole Show Attenuated Allergy Responses through the Induction of Regulatory $\mathbf{T}$ Cells in the Intestinal Mucosa}

\author{
Takahiro KobaYashi ${ }^{1)}$, Satoshi InO ${ }^{* 1)}$, Hiroki IshIKAWA ${ }^{1)}$, \\ ${\text { Chikara } \text { KoHDA }^{1)} \text {, Masatsugu NAgAhama }}^{2)}$ and Kazuo TANAKA ${ }^{1)}$
}

\begin{abstract}
This study sought to determine whether antibiotic treatments affect the pathogenesis of allergic diseases. We demonstrated that mice treated with a mixture of four antibiotic agents (ampicillin, neomycine, metronidazole, and vancomycin) showed significantly decreased antigen-specific $\operatorname{IgE}$ production compared to control mice, whereas mice treated with the same cocktail without metronidazole showed no change in IgE production compared to controls. Regulatory $\mathrm{T}$ cell suppression induced by particular antibody combinations is a possible mechanism of this effect, with an increased frequency of regulatory $\mathrm{T}$ cells also observed in the mesenteric lymph nodes (MLN) of mice treated with the mixture of four antibiotics, but not in the second cocktail without metronidazole. Our antibiotic treatments also dramatically decreased the diversity of mouse intestinal microbiota compared to control mice, based on 16SrRNA analysis of the cecum fecal composition. In conclusion, mice treated with antibiotic mixtures containing metronidazole, but not those treated without metronidazole, showed attenuated allergy responses and increased induction of regulatory $\mathrm{T}$ cells in the mucosa.
\end{abstract}

Key words : metronidazole, allergy, regulatory $\mathrm{T}$ cell, antibi

\section{Introduction}

Allergic diseases including food allergy, hay fever, bronchial asthma, allergic sinusitis, and atopic dermatitis are steadily increasing in prevalence, particularly in highly industrialized countries. In contrast, no such increases have been noted in developing countries ${ }^{1)}$. One possible explanation for this geographical anomaly is the higher frequency of antibiotic administration to infants with infectious diseases in developed countries leading to more cases of gut microbiota dysbiosis. This could in turn result in an insufficient mature immune system that predisposes the individual to Th2 allergic responses ${ }^{2)}$. Indeed, frequency of antibiotic usage is positively correlated with the incidence of allergic diseases ${ }^{3)}$, although interestingly, the excess use of antibiotics is considered a risk factor for allergic diseases in infants, but not in adolescents and adults who possess a fully

\footnotetext{
1) Department of Microbiology, Showa University School of Medicine, 1-5-8 Hatanodai, Shinagawa-ku, Tokyo 142-8555, Japan.

2) Department of Medicine, Division of Gastroenterology, Showa University Fujigaoka Hospital.

* To whom corresponding should be addressed.
} 
mature immune system ${ }^{4)}$. The mechanisms underlying this difference remain unclear, as does the risk level for administering antibiotics to allergy patients is unclear.

Among the various types of allergic diseases, antigen-specific $\operatorname{IgE}$ on mast cells under the mucosal surface plays a crucial role in the induction of allergy ${ }^{5)}$. After antigen exposure, these $\mathrm{IgE}$ molecules recognize the antigen, and histamines are released from the activated mast cells to increase downstream allergic responses ${ }^{6}$. Thus, the presence of antigen-specific $\operatorname{IgE}$ is a risk factor for all allergic diseases in the host. On the other hand, regulatory $\mathrm{T}$ cells can participate in inhibiting allergic responses ${ }^{7)}$, presumably by suppressing conventional $\mathrm{T}$ cell responses to activate allergic responses through multiple pathways, including TGF- $\beta$, IL-10, IL-35, CTLA-4, and Fas- $\mathrm{L}^{8)}$. In addition, regulatory $\mathrm{T}$ cell activity in the gut mucosa is closely related to the composition of gut microbiota ${ }^{9)}$, with certain species of bacteria and/or their metabolites, such as short-chain fatty acids, implicated in the induction of regulatory $\mathrm{T}$ cells in the gut mucosa ${ }^{10)}$.

In the present study, we investigated whether antibiotic usage affects allergic disease conditions, the frequency of regulatory $\mathrm{T}$ cells, and the gut microbiota. Moreover, we also investigated whether specific antibiotics change the risk of allergic diseases in a mouse allergy model.

\section{Materials and methods}

\section{Mice and treatments}

Female Balb/c mice were purchased from Oriental Yeast Co., Ltd. (Tokyo, Japan). All mice were housed under specific pathogen-free conditions and according to the animal protocol guidelines of the Institutional Animal Care and Use Committee of Showa University (Protocol No. 07034). Antibiotic treatment of mice was performed according to previous reports ${ }^{11)}$. Briefly, as shown in Figure 1, five-week-old mice were given ad libitum access to water or water containing antibiotics (ampicillin [AMP; $1 \mathrm{mg} / \mathrm{ml}$, neomycin [NEO; $1 \mathrm{mg} / \mathrm{ml}$, metronidazole $[\mathrm{MNZ} ; 1 \mathrm{mg} / \mathrm{ml}]$, and vancomycin $[\mathrm{VCM} ; 0.5 \mathrm{mg} / \mathrm{ml}]$ ) from day 1 to 5 and from day 10 to 15 . The day on which the administration of antibiotics was started was defined as day 1 in the experiments. In other experiments, mice received water containing a combination of three antibiotics from day 1 to 5 and from day 10 to 15 . Allergy was induced in some mice

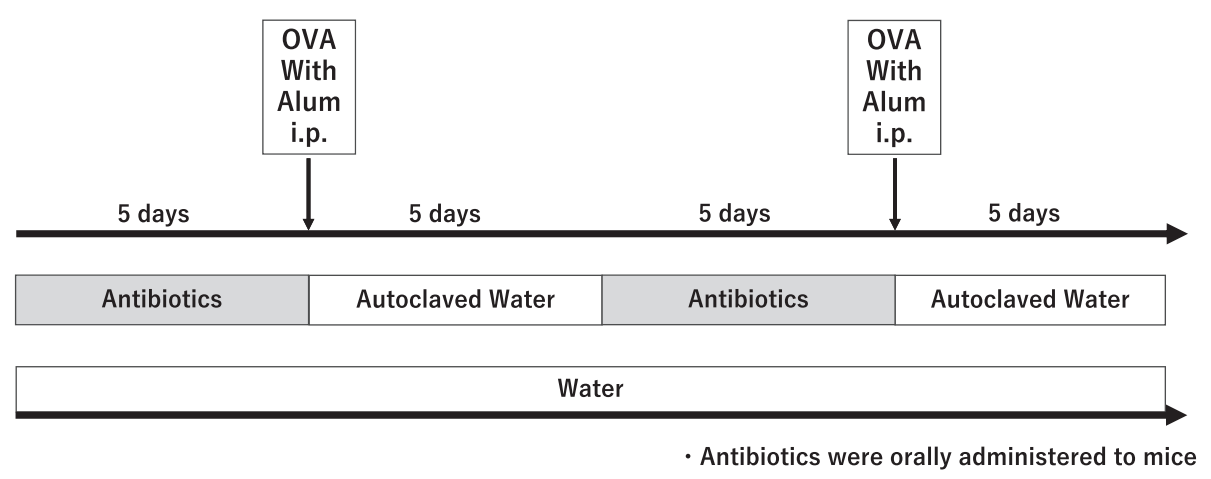

Fig. 1. The experimental designs in the current study Designs of the antibiotic administration experiments and the allergy induction model in the current study are shown. 
by intraperitoneal injection of $1 \mu \mathrm{g}$ of ovalbumin and $0.1 \mathrm{mg}$ of aluminum hydroxide (alum) (Thermo Scientific, IL, USA) at days 5 and 10, to increase the serum level of ovalbumin-specific IgE. Serum was collected from the mice on day 20.

\section{Measurement of ovalbumin-specific antibody}

Ovalbumin-specific $\mathrm{IgE}$ and the serum concentrations of $\mathrm{IgG}_{1}$ were measured by ELISA methods. Briefly, ovalbumin $(50 \mu \mathrm{g} / \mathrm{ml})$ was coated onto 96-well immunoplates overnight. After blocking with T20 (Thermo Scientific), the serum sample or ovalbumin-specific IgE antibody (Ab) standard (Acris Antibodies, San Diego, CA, USA) and biotin-conjugated anti-mouse IgE $\mathrm{Ab}$ (Southern Biotech, Birmingham, AL, USA) were then plated in the wells and incubated for $1 \mathrm{~h}$. After washing, horseradish peroxidase (HRP)-conjugated streptavidin was added before the detection of ovalbumin-specific antibodies using a 3, 3', 5, 5'-tetramethylbenzidine (TMB) microwell peroxidase substrate system (KPL, Gaithersburg, MD, USA). Absorbance at $450 \mathrm{~nm}$ was measured after the addition of a stop solution ${ }^{12)}$. In the same way as above, serum concentrations of $\mathrm{IgG}_{1}$ were measured using ovalbumin-specific $\mathrm{IgG}_{1} \mathrm{Ab}$ standard (Santa Cruz Biotechnology, Dallas, TX, USA) and biotin-conjugated anti-mouse $\operatorname{IgG}_{1} \mathrm{Ab}$.

\section{Flow cytometry}

Mice were given water or water containing antibiotics from day 1 to 5, and then spleen and mesenteric lymph nodes (MLN) cell suspensions were prepared for flow cytometry, using the following antibodies: anti-CD16/CD32 Ab as an Fc-blocker, FITC-conjugated anti-CD4 Ab, BV421-conjugated anti-CD25 Ab, Alexa Fluor-conjugated anti-Foxp3 Ab (BD Biosciences, San Jose, CA, USA), BV650-conjugated anti-CD3 Ab, FITC-conjugated anti CD19 Ab, and PE/Cy7conjugated anti-IL-10 Ab (BioLegend, San Diego, CA, USA). A Zombie red Fixable Viability Kit (BioLegend) was used to exclude dead cells, according to the manufacturer's protocol. Following the staining of surface antigens, intracellular Foxp3 staining was performed using a Transcription Factor Buffer set (BD Biosciences) ${ }^{13)}$. For intracellular IL-10 staining, a single cell suspension was incubated with LPS $(10 \mu \mathrm{g} / \mathrm{ml})$, PMA $(50 \mathrm{ng} / \mathrm{ml})$, ionomycin $(500 \mathrm{ng} / \mathrm{ml})$, and Brefeldin A $(1 \mu \mathrm{g} / \mathrm{ml})$ for $5 \mathrm{~h}$ at $37^{\circ} \mathrm{C}$ followed by intracellular IL-10 staining performed using a Transcription Factor Buffer set ${ }^{14)}$. All cells were analyzed by an LSR Fortessa flow cytometer (BD Biosciences). Cells positive for CD4, CD25, and intracellular Foxp3 were identified as regulatory $\mathrm{T}$ cells, while those positive for CD19 and intracellular IL-10 were identified as regulatory $\mathrm{B}$ cells.

\section{Microbiota composition analysis}

Mice were given water or water including antibiotics from day 1 to 5 , and then the cecum contents were collected. A microbiome composition analysis was performed by 16SrRNA sequence analysis at Techno Suruga Laboratory Co., Ltd. (Shizuoka, Japan). The bacterial count was determined by first culturing the cecum content suspensions serially diluted with PBS on Gifu Anaerobic Medium agar for 48 hours, and then calculating the $\log _{10}$ colony forming units (CFU)/g. 


\section{Statistical analysis}

Tukey's test was used for multiple comparisons, while the t-test was used for comparisons between groups. $P$ values $<0.05$ were considered to indicate statistical significance.

\section{Results}

Antibiotic treatment attenuated the allergy responses in mice

Mice first received a four-antibiotic mixture (AMP, NEO, MNZ, and VCM) from day 1 to 5 and from 10 to 15 , and then were injected with ovalbumin and alum to induce ovalbuminspecific $\mathrm{IgE}$ and $\mathrm{IgG}_{1}$ responses. The production of serum ovalbumin-specific $\mathrm{IgE}$ and $\mathrm{IgG}_{1}$ was significantly suppressed in the antibiotic-treated mice compared to control mice (antibiotic-treated vs. control : $\mathrm{IgE}: 71.5[53.0-76.0] \mathrm{ng} / \mathrm{ml}$ vs. $159.5[158.3-213.2] \mathrm{ng} / \mathrm{ml} ; \mathrm{IgG}_{1}: 45.4[39.9-61.6] \mathrm{ng} / \mathrm{ml}$ vs. $85.2[80.5-120.0] \mathrm{ng} / \mathrm{ml}$ ) (Fig. 2).

Regulatory $T$ cells induced mucosal immunity after treatment with the four-antibiotic mixture

Based on the antibiotic-induced suppression of ovalbumin-specific $\operatorname{IgE}$ and $\operatorname{IgG}_{1}$ production, we next investigated the induction of regulatory $\mathrm{T}$ cells and $\mathrm{B}$ cells. The MLN of mice treated with the four-antibiotic mixture (AMP, NEO, MNZ, VCM) from day 1 to 5 showed significantly increased numbers of regulatory $\mathrm{T}$ cells (the ratios of $\mathrm{CD} 4+\mathrm{CD} 25+$ Foxp $3+\mathrm{T}$ cells to the total $\mathrm{T}$ cells) compared to the control mice (antibiotic-treated mice, 8.8\% [8.6\%-10.3\%]; control mice, $5.3 \%[3.8 \%-6.0 \%]$ ) (Fig. 3). In contrast, the frequencies of regulatory $\mathrm{T}$ cells and $\mathrm{B}$ cells in same mouse spleens were comparable to those of control mice. Thus, administering one or more antibiotics increased the frequency of regulatory $\mathrm{T}$ cells in the MLN.

Regulatory $T$ cells were induced by treatment only by the mixture of antibiotics with metronidazole

We performed the following experiments to further decipher the effect of individual antibiotics on regulatory $\mathrm{T}$ cell activity. Mice received the following mixtures of antibiotics (four agents
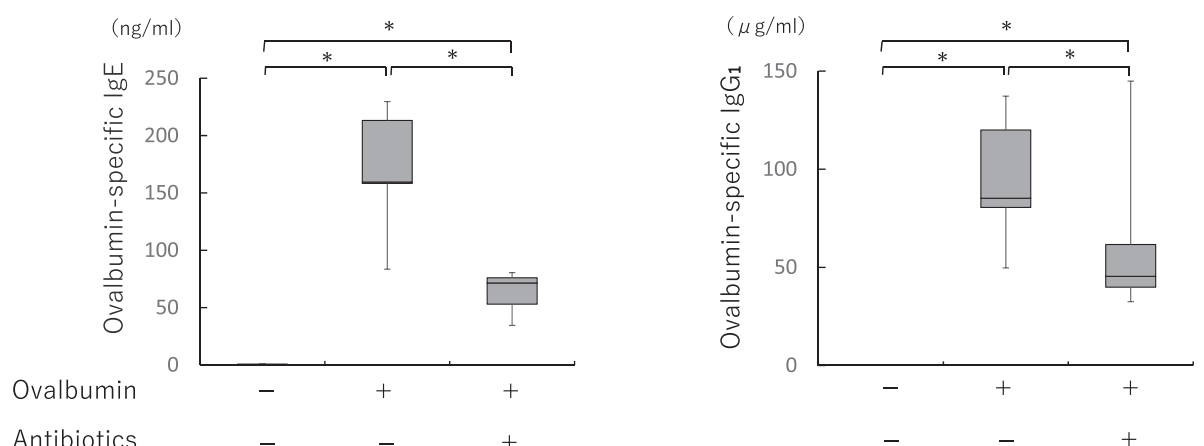

Fig. 2. The effect of antibiotic administration on the mouse allergy model A mixture of four antibiotics was administered to the mice from day 1 to 5 and from day 10 to 15 . The mice were injected with ovalbumin and alum on days 5 and 15. Serum samples were collected on day 20. The concentrations of ovalbumin-specific $\mathrm{IgE}$ and $\mathrm{IgG}_{1}$ were measured by ELISA $(\mathrm{n}=5-7) .{ }^{*} P<0.05$. 


\section{A. MLN}

(\%)

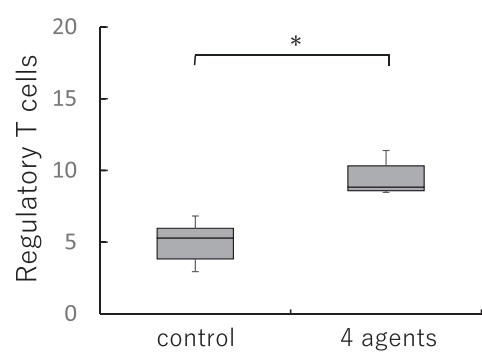

B. Spleen

(\%)

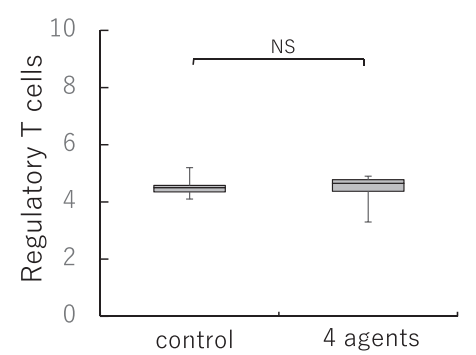

C. Spleen

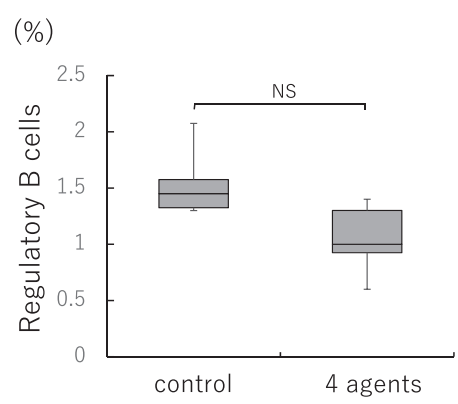

Fig. 3. The frequencies of regulatory $\mathrm{T}$ cells in the spleen and mesenteric lymph nodes (MLN), and the frequency of regulatory B cells in the spleen, as determined by flow cytometry

The frequencies of regulatory $\mathrm{T}$ cells and regulatory $\mathrm{B}$ cells in mice treated with the mixture of four antibiotic agents from day 1 to 5 . MLN and Spleen samples were collected on day 5 .

$\mathrm{A}$ : The frequency of $\mathrm{CD} 4{ }^{+} \mathrm{FOXP} 3^{+} \mathrm{CD} 25^{+}$cells (regulatory $\mathrm{T}$ cells) in the MLN of mice treated with four antibiotic agents and control mice.

$\mathrm{B}$ : The frequency of $\mathrm{CD} 4{ }^{+} \mathrm{FOXP} 3{ }^{+} \mathrm{CD} 25^{+}$cells (regulatory $\mathrm{T}$ cells) in the spleen of mice treated with four antibiotic agents and control mice.

$\mathrm{C}$ : The frequency of $\mathrm{IL}-10^{+} \mathrm{CD} 19^{+}$cells (regulatory B cell) in the spleen of mice treated with four antibiotic agents and control mice $\left(n=5^{-7}\right)$.

${ }^{*} P<0.05$. NS : Not significant.

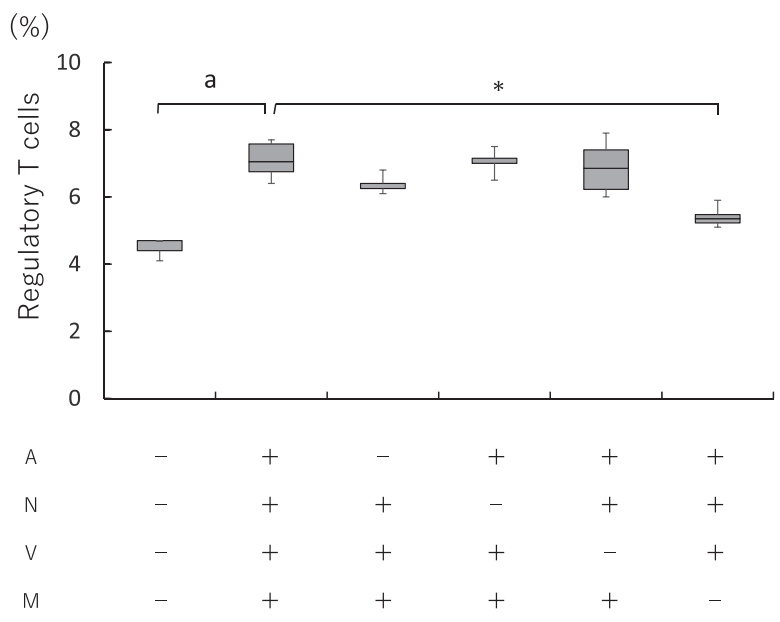

Fig. 4. The frequency of regulatory $\mathrm{T}$ cells in the MLN, as determined by flow cytometry Mice were treated with a mixture of three or four antibiotic agents from day 1 to 5. Spleen cells were obtained on day 5. The frequency of $\mathrm{CD} 4{ }^{+} \mathrm{FOXP} 3{ }^{+} \mathrm{CD} 25^{+}$cells in the MLN from mice that received a mixture of three antibiotic agents (without MNZ) were significantly lower in comparison to the mice that received four antibiotic agents $(n=5)$.

$\mathrm{A}$ : ampicillin, $\mathrm{M}$ : metronidazole, $\mathrm{N}$ : neomycin, $\mathrm{V}$ : vancomycin. ${ }^{*} P<0.05$. a : $P=0.053$.

[AMP, NEO, MNZ, VCM], three agents [NEO, MNZ, VCM], [AMP, MNZ, VCM], [AMP, $\mathrm{NEO}, \mathrm{MNZ}$ ], or [AMP, NEO, VCM]) or autoclaved water. The frequencies of regulatory $\mathrm{T}$ cells were as follows: $7.1 \%(6.8-7.6 \%)$ for 4 agents, 6.4\% (6.3-6.4\%) for NEO, MNZ, and VCM, 7.0\% (7.0-7.2\%) for AMP, MNZ, and VCM, 6.9\% (6.2-7.4\%) for AMP, NEO, and MNZ, 5.4\% (5.2-5.5\%) for AMP, NEO, and VCM, and 4.7\% (4.4-4.7\%) for autoclaved water (Fig. 4). The frequency of regulatory $\mathrm{T}$ cells was significantly lower in mice that received the antibiotic 

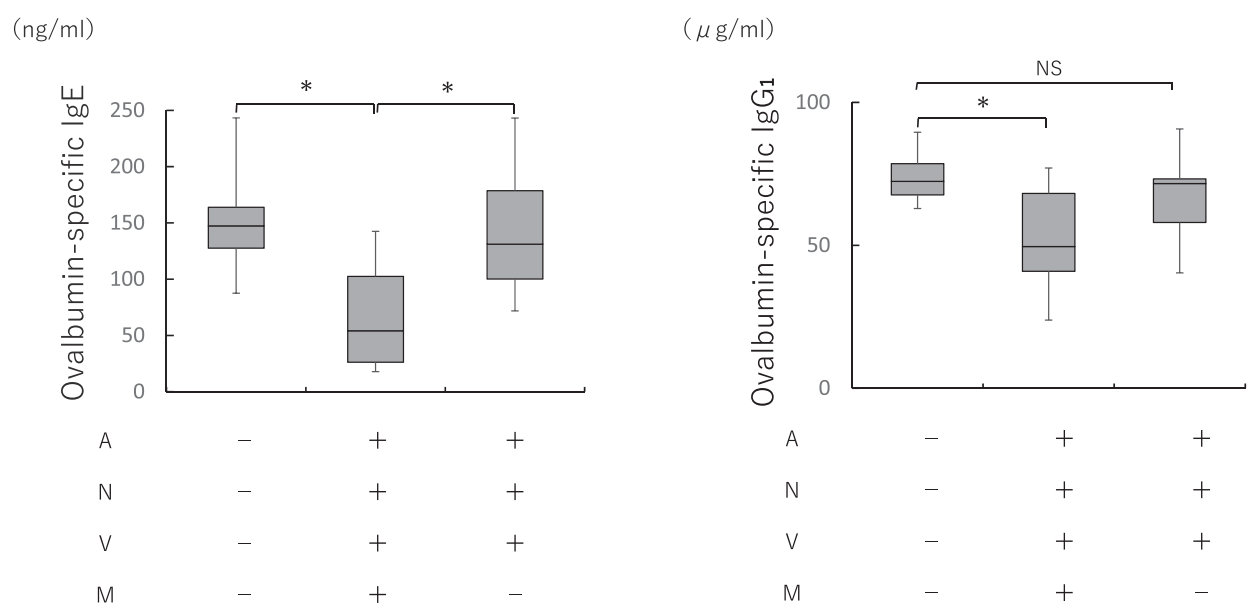

Fig. 5. The influence of antibiotic administration on the gut microbiota based on $\mathrm{IgE}$ and $\mathrm{IgG}_{1}$ levels

Mice were treated with a mixture of four antibiotic agents or three antibiotic agents without MNZ from day 1 to 5 and from day 10 to 15 , and then injected with ovalbumin and alum on days 5 and 15. Serum samples were collected on day 20. The concentrations of ovalbumin-specific $\operatorname{IgE}$ and $\operatorname{IgG}_{1}$ were measured by ELISA $(n=7)$.

A : ampicillin, $\mathrm{M}$ : metronidazole, $\mathrm{N}$ : neomycin, $\mathrm{V}$ : vancomycin.

${ }^{*} P<0.05$. NS : Not Significant.

mixtures without MNZ, in comparison to the mice that received four antibiotics. Interestingly, mice treated with the three-antibody combinations without metronidazole showed significantly increased ovalbumin-specific IgE production compared to the mice treated with four antibiotics (71.6 [58.0-73.2] ng/ml vs. $49.5[40.9-68.1] \mathrm{ng} / \mathrm{ml})$; however, no such differences were found in the production of ovalbumin-specific $\operatorname{IgG}_{1}$ (Fig. 5). Thus, the antibiotic mixtures containing MNZ induced regulatory $\mathrm{T}$ cells in the MLN of mice that suppressed the allergic response.

The 16SrRNA analysis and culturing revealed that antibiotic treatments cause remarkable change to the composition of gut microbiota

We next investigated whether the microbiota composition was affected by antibiotic treatment. As shown in Figure 6, mice treated with the mixture of four antibiotics showed significantly reduced bacterial diversity in the microbiota compared to the control mice, with the microbiota dominated by Escherichia species. On the other hand, the microbiota samples from mice treated with the three-antibiotic mixtures not containing metronidazole were dominated by Clostridium sensu stricto. Moreover, bacterial counts in the feces of mice receiving antibiotic mixtures with and without $\mathrm{MNZ}$ were similarly reduced (Control: $8.43 \log _{10} \mathrm{CFU} / \mathrm{g}, 4$ agents : $3.81 \log _{10} \mathrm{CFU} / \mathrm{g}$, 4 agents : $3.91 \log _{10} \mathrm{CFU} / \mathrm{g}$ ). These results suggest that antibiotic treatment had a remarkable effect on the microbiota of mice.

\section{Discussion}

It remains unclear whether antibiotic treatment is a risk factor for the exacerbation of allergic diseases or a beneficial factor that attenuates allergic diseases. Moreover, no studies have 


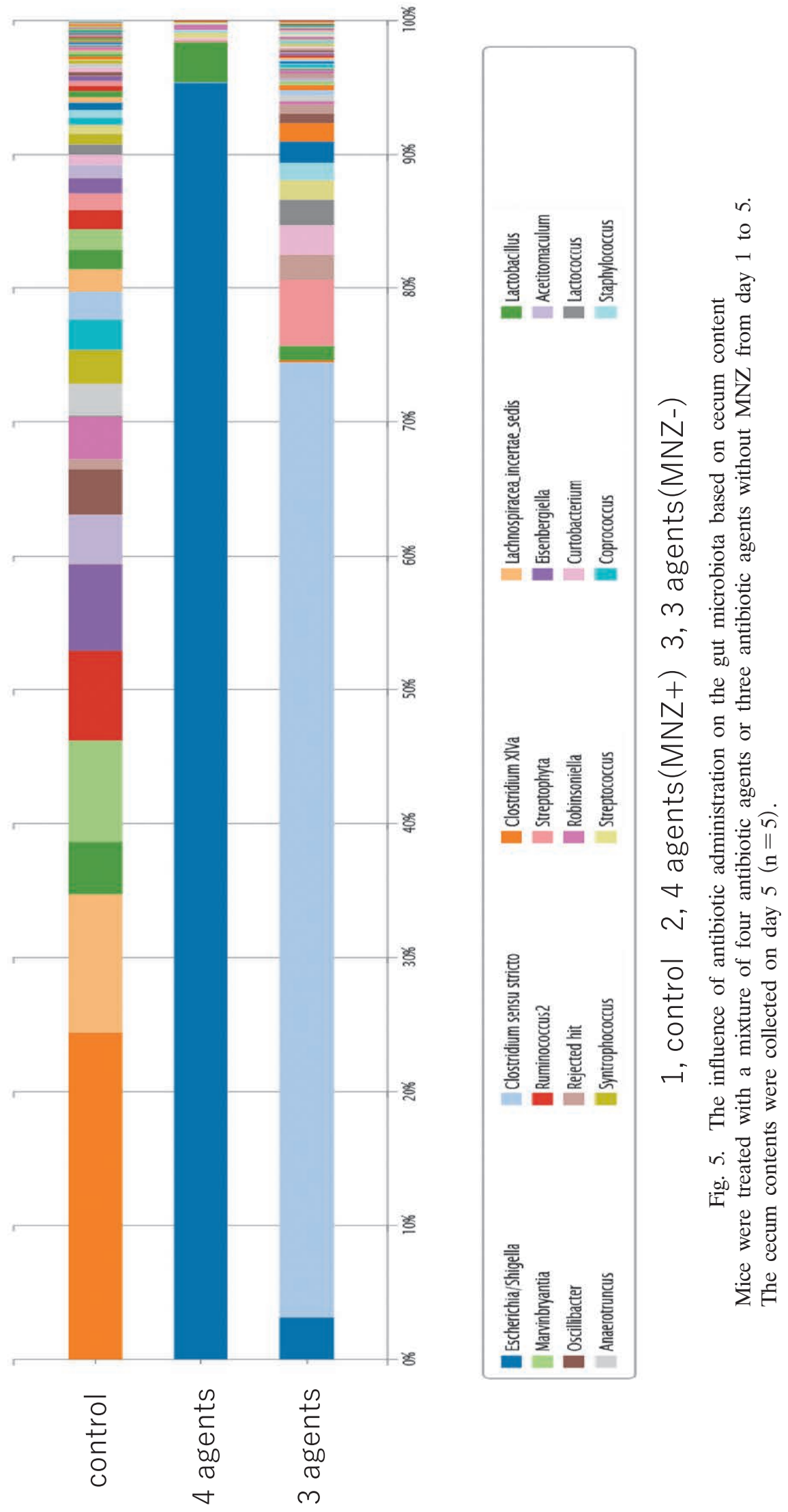


examined differences among antibiotic types with respect to allergic response. The current study demonstrated in mice that administering mixtures of four and three antibiotic agents, but not three antibiotic agents without metronidazole, reduced the production of systemic antigen-specific $\mathrm{IgE}$ through inducing regulatory $\mathrm{T}$ cells into the mucosa.

Several reports have linked usage of antibiotics in infancy and early childhood to an increased risk of allergic diseases due to changes in the composition of gut microbiota ${ }^{15-17)}$. In addition, epidemiological studies have shown differences in microbiota composition and less diversity in the microbiota of children with allergic diseases compared to healthy children ${ }^{18,19)}$. The gut microbiota, especially antibiotic-sensitive-bacteria, could potentially both limit the development pro-inflammatory cells and promote the maturation of regulatory cells. Thus, antibiotic use in infancy and early childhood could lead to abnormal immune development. Interestingly, our study also indicated that this effect might differ among antibiotic types. Almqvist et $a l^{20)}$ indicated a strong relationship between the use of antibiotics to treat gram-positive bacterial infections and the development of allergic diseases, while no such relationship was observed with antibiotics used for gram-negative bacterial infections. Moreover, use of antibiotics by adult patients with allergic diseases did not affect their clinical condition ${ }^{4)}$. Thus, we investigated whether antibiotic-sensitive bacteria in the gut microbiota could attenuate the induction of allergic diseases and/or exacerbate the development of allergic diseases, in association with modulation of the microbiota and host immunity.

We showed that treatment with a cocktail of four antibiotic agents reduced systemic ovalbumin-specific IgE production, and it is possible that such a response could reflect the mucosal induction of regulatory $\mathrm{T}$ cells. The gut microbiota in four-antibiotic treated mice was dominated by the Escherichia/shigella genus; however, the overall diversity of the gut microbiota was decreased in comparison to control mice. LPS and flagellin are present on the cell surface of the Escherichia/shigella genus (gram-negative bacteria), and these molecules can stimulate peripheral naïve $\mathrm{T}$ cells via TLR-4 and TLR-5, respectively, inducing regulatory $\mathrm{T}$ cells ${ }^{21)}$. Therefore, inducing regulatory $\mathrm{T}$ cells might suppress $\mathrm{IgE}$ production by $\mathrm{B}$ cells through several immunosuppressive mechanisms ${ }^{22}$. Indeed, LPS exposure can have a protective effect against Th2-type airway inflammation and airway hyperresponsiveness in murine models ${ }^{23,24)}$. On the other hand, the ovalbumin-specific IgE production of mice treated with three antibiotic agents without metronidazole in this study was comparable to that of control mice. One possible explanation for this apparent anomaly is that that the gut microbiota in the treated mice was dominated by the Clostridium sensu stricto genus, which is also a major component of the gut microbiota in infants with food allergy and is strongly associated with food allergy in infancy ${ }^{25)}$. Moreover, the prevalence of Clostridium sensu stricto is positively associated with IgE-mediated food allergy, although the mechanisms of serum IgE production in infants with Clostridium sensu stricto-associated food allergy are unknown ${ }^{25)}$.

In conclusion, we showed that treatment with a cocktail of four antibiotic agents attenuated allergic responses through the induction of regulatory $\mathrm{T}$ cells; however, leaving metronidazole out of the treatment did not affect the allergy responses or induce regulatory $\mathrm{T}$ cells. Further 
studies are thus required to identify bacteria and / or metabolites, such as short-chain fatty acids, that induce regulatory $\mathrm{T}$ cells in the mucosa. We will also investigate whether regulatory $\mathrm{T}$ cells in the MLN induced by treatment with the four-antibiotic cocktail can suppress antigen-specific $\mathrm{IgE}$ production, and in turn, allergic diseases using an adaptive transfer model.

\section{Conflict of interest disclosure}

The authors declare no conflict of interest associated with this manuscript.

\section{References}

1) The intestinal study of asthma and allergies in childhood (ISSAC) steering committee. Worldwide variation in prevalence of symptoms of asthma, allergic rhinoconjuctivitis, and atopic eczema: ISAAC. Lancet. 1998;351:12251232.

2) Sudo N, Sawamura S, Tanaka K, et al. The requirement of intestinal bacterial flora for the development of an IgE production system fully susceptible to oral tolerance induction. J Immunol. 1997;159:1739-1745.

3) Oyama N, Sudo N, Sogawa H, et al. Antibiotic use during infancy promotes a shift in the $T(H) 1 / T(H) 2$ balance toward T(H)2-dominant immunity in mice. J Allergy Clin Immunol. 2001;107:153-159.

4) Honda K, Littman DR. The microbiome in infectious disease and inflammation. Annu Rev Immunol. 2013;30:759795.

5) Galli SJ, Tsai M. IgE and mast cells in allergic disease. Nat Med. 2012;18:693-704.

6) Oettgen HC. Fifty years later: emerging functions of IgE antibodies in host defense, immune regulation, and allergic diseases. J Allergy Clin Immunol. 2016;137:1631-1645.

7) Tsuji S, Suruda C, Hashiyada M, et al. Gut microbiota dysbiosis in children with relapsing idiopatic nephrotic syndrome. Am J Nephrol. 2018;47:164-170.

8) Sojka DK, Huang YH, Fowell DJ. Mechanisms of regulatory T-cell suppression - a diverse arsenal for a moving target. Immunology. 2008;124:13-22.

9) Furusawa Y, Obata Y, Fukuda S, et al. Commensal microbe-derived butyrate induces the differentiation of colonic regulatory T cells. Nature. 2013;504:446-450. Erratum in: Nature. 2014;506:254.

10) Lee WJ, Hase K. Gut microbiota-generated metabolites in animal health and disease. Nat. Chem. Biol. 2014; 10:416-424.

11) Chadchan SB, Cheng M, Parnell LA, et al. Antibiotic therapy with metronidazole reduces endometriosis disease progression in mice: a potential role for gut microbiota. Hum Reprod. 2019;34:1106-1116.

12) Ino S, Koda $\mathrm{C}$, Takeshima $\mathrm{K}$, et al. Oral tolerance is inducible during active dextran sulfate sodium-induced colitis. World J Gastrointest Pharmacol Ther. 2016;7:242-253.

13) Dutsch-Wicherek MM, Szubert S, Dziobek K, et al. Analysis of the treg cell population in the peripheral blood of ovarian cancer patients in relation to the long-term outcomes. Ginekol Pol. 2019;90:179-184.

14) Hong C, Gao X. Purification and immunophenotypic characterization of murine B10 B cells. Methods Mol Biol. 2014;1190:35-44.

15) Noverr MC, Huffnagle GB. The 'microflora hypothesis' of allergic diseases. Clin Exp Allergy. 2005;35:1511-1520.

16) Pascal M, Perez-Gordo M, Caballero T, et al. Microbiome and Allergic Diseases. Front Immunol. 2018;9:1584. (accessed 2019 Feb 8) Available from: https://www.ncbi.nlm.nih.gov/pmc/articles/PMC6056614/pdf/fimmu-09-01584. pdf

17) Eggesbo M, Moen B, Peddada S, et al. Development of gut microbiota in infants not exposed to medical interventions. Acta Pathol Microbiol Immunol. 2011;119:17-35.

18) Sjogren YM, Jenmalm MC, Bottcher MF, et al. Altered early infant gut microbiota in children developing allergy 
up to 5 years of age. Clin Exp Allergy. 2009;39:518-526.

19) Bisgaard H, Li N, Bonnelykke K, et al. Reduced diversity of the intestinal microbiota during infancy is associated with increased risk of allergic disease at school age. J Allergy Clin Immunol. 2011;128:646-652.

20) Almqvist C, Wettermark B, Hedlin G, et al. Antibiotics and asthma medication in a large register-based cohort study - confounding, cause and effect. Clin Exp Allergy. 2012;42:104-111.

21) Woo JG, Assa'ad A, Heizer AB, et al. The $-159 \mathrm{C}-->\mathrm{T}$ polymorphism of CD14 is associated with nonatopic asthma and food allergy. J Allergy Clin Immunol. 2003;112:438-444.

22) Hill DA, Siracusa MC, Abt MC, et al. Commensal bacteria-derived signals regulate basophil hematopoiesis and allergic inflamation. Nat Med. 2012;18:538-546.

23) Gerhold K, Avagyan A, Seib C, et al. Prenatal initiation of endotoxin airway exposure prevents subsequent allergen-induced sensitization and airway inflammation in mice. J Allergy Clin Immunol. 2006;118:666-673.

24) Schuijs MJ, Willart MA, Vergote K, et al. Farm dust and endotoxin protect against allergy through A20 induction in lung epithelial cells. Science. 2015;349:1106-1110.

25) Ling Z, Li Z, Liu X, et al. Altered fecal microbiota composition associated with food allergy in infants. Appl Environ Microbiol. 2014;80:2546-2554.

[Received June 6, 2019 : Accepted July 16, 2019] 